\title{
REFLEXÕES SOBRE O POTENCIAL PEDAGÓGICO DA MEDIAÇÃO DE CONFLITOS ${ }^{1}$
}

\author{
Klever Paulo Leal Filpo \\ Autor correspondente. Universidade Católica de Petrópolis - Centro de Ciências Jurídicas. Rua Benjamim Constant, 213 - Centro. Pe- \\ trópolis/RJ, Brasil. CEP 25610-130; Universidade Federal Rural do Rio de Janeiro - UFRRJ. http://lattes.cnpq.br/1619725989694017. \\ https://orcid.org/0000-0001-6882-4282 \\ klever.filpo@yahoo.com.br
}

Geovana Faza da Silveira Fernandes

Universidade Estácio de Sá - Unesa; Universidade Federal Fluminense - UFF. Rio de Janeiro/RJ, Brasil.

A proposta do artigo é refletir sobre o emprego da mediação para o tratamento de conflitos escolares e sobre a importância de uma educação pela mediação, considerando seu potencial pedagógico, e para a mediação, como condição de êxito para uma mudança de cultura e efetivação da Política Nacional de Tratamento Adequado dos Conflitos de Interesse, no Brasil. Contém revisão bibliográfica conjugada com o relato de experiências empíricas. Palavras-chave: Brasil; conflitos escolares; educação; mediação.

\section{REFLECTING ON THE PEDAGOGICAL POTENTIAL OF CONFLICTS MEDIATION}

ABSTRACT

The purpose of the article is to reflect on the use of conflict mediation for the treatment of school conflicts and on the importance of an education through mediation, considering its pedagogical potential, and for mediation, as a condition for the effectiveness of Brazilian National Policy for Appropriate Treatment of Conflicts of Interests. It contains a bibliographic review and the report of empirical experiences.

Keywords: Brazil; school conflicts; education; mediation.

Recebido em: $31 / 3 / 2020$

Aceito em: $31 / 5 / 2021$

Pesquisa realizada no âmbito de um PPGD com recursos do CNPq-Brasil. 


\section{Humanos e \\ Democracia}

\section{CONSIDERAÇÕES INICIAIS}

A proposta do presente artigo é pensar em uma educação para a mediação como condição de êxito para a denominada Política Nacional de Tratamento Adequado dos Conflitos de Interesse, no Brasil, contendo o relato de algumas experiências empíricas.

A despeito de todo o entusiasmo em torno da iniciativa de incorporar formas consensuais de solução de conflitos no Brasil, sobre o que trataremos mais adiante, há resistências e dificuldades, de ordem cultural e também estrutural, que se colocam como obstáculos à efetivação dessa política pública. Um desses obstáculos, que nos interessa neste texto, é a ausência de uma educação para as formas consensuais de solução de conflitos, ou seja, de iniciativas que permitam formar pessoas para pensar de modo diferenciado (em relação às formas convencionais de solução de conflitos pelo Judiciário) os conflitos interpessoais, e preparadas para lidar com eles, utilizando, sobretudo, as ferramentas da mediação (BRAGA NETO, 2012).

Metodologicamente, o texto contém revisão bibliográfica conjugada com o relato de experiências e dados de campo obtidos por meio de pesquisa empírica qualitativa que temos conduzido, com recursos do CNPq/Brasil (Chamada Universal 2016). ${ }^{2}$ Nossas abordagens empíricas incluem estudo de casos e observações realizadas com o objetivo de compreender o que faz com que um conflito surgido na escola seja judicializado, e os mecanismos acionados na tentativa de administrá-lo. Interessa também identificar, compreender e descrever a utilização (ou não) de formas consensuais de tratamento desses conflitos e os caminhos que seguem no sistema de justiça. O local da pesquisa é o município de Petrópolis, Rio de Janeiro, onde é desenvolvida no âmbito de um Programa de Pós-Graduação em Direito, envolvendo mestrandos e graduandos na área, voluntários e bolsistas.

Uma das questões que tem sobressaído na pesquisa é que há, no Brasil, uma cultura jurídica bastante arraigada (NICÁCIO, 2012) no sentido de que a solução de conflitos é tarefa do juiz. Modificar essa percepção demanda uma formação mais ampla para o consenso - em vez do litígio - tendo como destinatários não apenas os profissionais de formação jurídica, mas a população em geral. Essa constatação leva a uma pergunta que pretendemos explorar aqui: Tal formação, no contexto de um movimento nacional pelas soluções adequadas para os conflitos, não seria também um papel da escola?

Em nosso esforço para responder a essa pergunta, neste artigo, passaremos pela análise da Política Nacional de Tratamento Adequado aos Conflitos de Interesses, para, após, contextualizá-la no quadro mais amplo de transição de paradigmas e seu impacto na forma de se tratar fenômenos conflitivos. Essa mudança leva à adoção da mediação, bem como de outros meios consensuais, tanto no contexto do poder Judiciário quanto nas comunidades e escolas. Refletiremos, também, sobre a mediação como instrumento pedagógico e fomentador de uma mudança de cultura, de uma cultura beligerante para outra mais pacífica.

Feito um breve percurso teórico, traremos considerações, a partir de experiências de campo, como forma de exemplificar como a mediação pode ser aplicada no contexto escolar

Este texto é resultado de discussão permanente que temos estabelecido em diversos espaços acadêmicos e educacionais, enfocando aspectos culturais e jurídicos da mediação de conflitos, fruto de pesquisa realizada com recursos do CNPq-Brasil (Edital Universal 2016). 


\section{Democracia}

Humanos e

e também o hiato existente entre o que pensamos ser ideal e o que a realidade mostra. A efetivação da política pública de tratamento adequado para os conflitos de interesse necessita ser objeto de reflexões, levando-se em conta tanto o arcabouço teórico que reveste o tema quanto alguns dados obtidos em pesquisa de campo, que analisam as formas de sua efetivação, impactos e disseminação, e este é, enfim, o objetivo central da presente contribuição.

\section{POLITICA NACIONAL DE TRATAMENTO ADEQUADO PARA OS CONFLITOS DE INTERESSE NO BRASIL}

No campo da administração de conflitos sociais, vivemos hoje, no Brasil, sob os influxos da chamada Política Nacional de Tratamento Adequado dos Conflitos de Interesse, que vem estimulando a utilização de meios consensuais, como a conciliação e a mediação, em diferentes contextos (MELLO; BAPTISTA, 2011).

Segundo Gianezini (2017), estabelecer um conceito unívoco de política pública é algo complexo, pois "não há uma teoria completa e definida sobre o tema, mas sim vários conceitos que formam o que pode ser traduzido como política pública." A mesma autora informa que as políticas públicas estão diretamente associadas ao Estado, contudo há outros atores que agem na sua construção, tanto no âmbito privado como público. E propõe:

A partir dessas constatações, as políticas públicas são, então, espaços (ou campos) que contemplam conhecimentos teóricos - da parte da academia - e empíricos - emanados mediante discursos de cidadãos que procuram promover a ação governamental ou recomendar possíveis alterações nessas ações. Destarte, as políticas públicas são, em verdade, as intenções governamentais que produzirão transformações profundas ou artificiais no mundo real (GIANEZINI, 2017, p. 1.070).

Temos sustentado que todos os esforços que vêm sendo empreendidos, aproximadamente nos últimos 15 anos, a fim de disseminar o emprego de métodos consensuais de solução de conflitos no Brasil como alternativa aos serviços judiciários prestados pelo Estado, podem ser considerados uma política pública. Tal política foi em muito influenciada pela atuação do Judiciário desde a criação do Conselho Nacional de Justiça (2004), consolidando-se a partir da Res. 125/2010 desse Conselho (NUNES, 2014). Sob a ótica do poder Judiciário, parece haver a intenção de evitar ao máximo a judicialização das disputas, preferindo que estas sejam contornadas, administradas ou mesmo solucionadas por outras vias, como a mediação extrajudicial (FILPO, 2016).

Nessa medida tem-se buscado estimular, de diversas maneiras, as chamadas soluções amigáveis ou não adversariais (AZEVEDO, 2012) para os conflitos de interesses, em diferentes contextos. A Lei 13.105/2015 absorveu essa proposta ao incluir, no procedimento comum cível (artigo 334) a obrigatoriedade de realizar audiências de mediação quando as partes em conflito estão ligadas em relações continuadas (de família e de vizinhança, por exemplo). Ou ainda, antes, quando o artigo 3 o do Código convoca todos os atores processuais para incentivarem o emprego das soluções consensuais para os conflitos. Por outro lado, a Lei de Mediação (13.140/2015) buscou regulamentar o emprego da mediação nos mais diferentes contextos, tanto em sede judicial como extrajudicial, chegando ao ponto de autorizar que se realize para dirimir conflitos envolvendo a administração pública, quando se tratar de direitos indisponíveis, mas que comportem transação. Ressalte-se, também, a edição da Res. 225/2016, 


\section{Democracia}

Humanos e

que insere no quadro da política nacional de tratamento adequado dos conflitos de interesses a justiça restaurativa.

A Res. 225/2016 releva a fundamentação da adoção da Justiça Restaurativa no direito ao acesso formal e substancial à Justiça, previsto no artigo 5ㅇ, XXXV, da Constituição Federal, ao argumento de que, além da vertente formal perante os órgãos judiciários, ele "implica o acesso a soluções efetivas de conflitos por intermédio de uma ordem jurídica justa e compreende o uso de meios consensuais, voluntários e mais adequados a alcançar a pacificação de disputa" (BRASIL, 2016), sejam esses praticados dentro da estrutura judiciária ou fora dela, em ambientes comunitários, escolares, etc.

Convém frisar, ainda, que nos considerandos da norma, o CNJ pontua a importância de se levar em conta, para fins de administração dos conflitos e de cenários de violência, não somente "aspectos relacionais individuais, mas também os comunitários, institucionais e sociais que contribuem para seu surgimento, estabelecendo-se fluxos e procedimentos que cuidem dessas dimensões e promovam mudanças de paradigmas, bem como, provendo-se espaços apropriados e adequados" (BRASIL, 2016). Nota-se, portanto, um esforço do poder público em estimular e fomentar práticas consensuais para além da arena institucional.

O estímulo a essa política e sua sedimentação no âmbito institucional, tão somente, não se mostram suficientes para a promoção de transformações significativas na forma como administramos nossos conflitos, ou seja, para que haja uma profunda conscientização acerca da importância da colaboração e do diálogo ético nos processos de resolução das controvérsias.

Nessa esteira, sustenta Kazuo Watanabe que os esforços devem ser acompanhados de mudança de mentalidade e de uma nova compreensão da realidade sociopolítica e econômica (1988, p. 129), sem a qual as mudanças estruturais e institucionais não adiantariam muito para auxiliar a compreensão acerca da importância dos métodos consensuais de resolução de conflitos. O jurista salienta, ainda, que "não se organiza uma justiça para uma sociedade abstrata, e sim para um país de determinadas características sociais, políticas, econômicas e culturais".

Considerando, pois, o contexto sociopolítico e econômico brasileiro, é necessário manter uma postura humilde diante dos incentivos à adoção dos meios consensuais como instrumentos de pacificação, fazendo-se necessário reconhecermos seus limites, principalmente se levarmos em conta as grandes desigualdades sociais e os problemas estruturais da sociedade brasileira, cujas raízes são profundas, demandando olhares para além da administração dos conflitos pelo poder Judiciário. De todo modo, há que se reconhecer que, em longo prazo, a adoção sistematizada desse método de resolução de conflitos, em diversos campos que não somente no limite institucional, pode trazer benesses em termos de empoderamento dos cidadãos, inclusão, educação e reconhecimento mútuo, que contribuem para a superação de fenômenos violentos e para a construção de práticas para a paz. São algumas das promessas da mediação, que dão suporte às reflexões aqui lançadas.

Em poucas linhas justifica-se, pois, a adoção da mediação em arenas externas ao poder Judiciário, e mesmo alheias à presença autoritária do próprio Estado, em sua face coercitiva. E por que a mediação em âmbito escolar? Aqui, saliente-se que, embora esteja implícito dentro desse movimento que a mediação teria ampla utilização na administração de variados tipos de conflitos, vem se consolidando a percepção de que ela seria mais adequada para 


\section{Democracia}

Humanos e

tratar daquelas disputas em que as partes, após a solução do problema específico, tenham de continuar se relacionando, como acontece entre vizinhos, entre pais separados com filhos, entre estudantes de uma mesma escola, membros de uma mesma agremiação, entre outros exemplos. É o que se denomina relações continuadas (AZEVEDO, 2012). Essa ideia foi, inclusive, trazida para o campo normativo pelo Código de Processo Civil, sedimentando a noção de que esse método é potencialmente mais adequado para as chamadas relações de múltiplos vínculos ou multiplexas, pressupondo que seu conteúdo emocional seja mais complexo, demandando, portanto, abordagens que permitam a consideração de questões subjacentes ao conflito expresso.

Os conflitos escolares parecem encaixar-se no contexto de relações continuadas, em que se recomenda o uso da mediação em lugar das soluções judiciais. Até mesmo para evitar que os jovens envolvidos em conflitos de diferentes naturezas acabem ingressando no sistema de Justiça, em vez de serem buscadas soluções educativas, próprias para a sua idade e formação.

O que se está denominando de conflitos escolares são aqueles que surgem no ambiente ou a partir das relações inerentes às atividades da escola, envolvendo alunos, professores, pais, responsáveis e outros atores. Em tais situações, recomenda-se que as próprias partes encontrem a melhor saída, em vez de esta ser imposta pelo Estado-Juiz (SIMIÃO, 2010; MARTíN, 2011), o que pode, inclusive, trazer consequências severas e indesejadas para esses jovens.

\section{MEDIAÇÃO E MUDANÇA DE PARADIGMAS}

A proposta de construir sociedades mais pacíficas passa pela conscientização de seus membros acerca da necessidade de se adotar métodos também mais pacíficos de resolução de conflitos. Podemos dizer que a forma preponderante como uma sociedade resolve seus conflitos diz muito de sua cultura, seus valores, do grau de realização dos direitos fundamentais. Nesse ponto, o que o quantitativo de 78 milhões de processos em tramitação no Brasil, segundo estatística publicada pelo CNJ em 2019, pode significar? ${ }^{3}$

Essa intensa hiperjudicialização possui raízes históricas, ligadas a processos de exclusão social, de violência estrutural, desigualdades, baixa densidade democrática, desempoderamento dos cidadãos. É senso comum afirmar que o fortalecimento da cultura de paz está intimamente ligado a transformações culturais, e que essas dependem, intrinsecamente, de mudanças nos cenários educacionais. Daí a importância da promoção de programas educacionais para os direitos humanos, de criação de espaços verdadeiramente participativos para as tomadas de decisão e resolução de controvérsias. Espaços de escuta e de vivência real da cidadania. E nada melhor do que começar na escola, ensinando a nossas crianças e jovens novas formas de se relacionarem com os demais quando o entendimento cede espaço para a disputa e para o conflito.

A mediação escolar, portanto, tem um escopo mais amplo do que a resolução de conflitos em contextos educacionais, ou seja, ela visa à preparação de nossos jovens para o exercí-

\footnotetext{
3 Conferir Relatório Justiça em Números do CNJ. Disponível em: https://www.cnj.jus.br/pesquisas-judiciarias/justica-emnumeros/. Acesso em: 31 mar. 2020.
} 


\section{Democracia}

Humanos e

cio da cidadania, participativa e direcionada à resolução pacífica das controvérsias e à prevenção da escalada da violência. E como isso é possível?

Aqui, a questão que se pode colocar diz respeito a como lidar com um conflito, de modo a potencializar seu poder transformador, convertendo-o em possibilidade de empoderamento, educação, construção de contextos mais pacíficos. John Paul Lederach propõe um método de transformação que intervém de forma a "produzir abordagens que minimizem os efeitos disfuncionais da comunicação e valorizem a compreensão mútua, trabalhando o contexto e os padrões dos relacionamentos que geraram o problema" (LEDERACH, 2012, p. 12), o que permite, segundo o sociólogo e mediador de conflitos complexos, tornar conscientes as capacidades dos indivíduos e prepará-los positivamente para lidar de forma construtiva com problemas futuros, independentemente de sua complexidade.

No contexto de uma sociedade complexa, cujos problemas são interconectados e interdependentes (CAPRA, 2014), faz-se necessária a adoção de meios de tratamento de conflitos que possam abarcar a complexidade dos dissensos, as particularidades socioculturais dos envolvidos e a exigência maior de participação direta dos interessados na construção das soluções. O século 21 , conforme muitos teóricos de diversos campos afirmam, demanda uma "mudança radical em nossa percepção, em nosso pensamento e em nossos valores", [...] por estarmos, justamente, no "princípio dessa mudança fundamental de visão de mundo na ciência e na sociedade, uma mudança de paradigmas tão radical quanto a revolução copernicana" (CAPRA; LUISI, 2014, p. 13).

Nesse horizonte é que deslindam as práticas autocompositivas, entre as quais encontra-se a mediação, que devem ser lentamente incorporadas na prática cotidiana de comunicação, desde a tenra idade, como estratégia de despolarização da comunicação entre confrontantes, na busca de um diálogo transformador que possibilite o entendimento, respeitando a alteridade existente em cada pessoa. Essa mudança de paradigmas se faz sentir em todos os campos do conhecimento humano: nas ciências naturais e também sociais (CAPRA; LUISI, 2014). No campo da Sociologia, do Direito, e aqui pode-se falar em um "novo Direito", as mudanças impactam na forma de se pensar o Estado e suas áreas de intervenção, na forma de delineamento da cidadania, no trato dos cidadãos e até na consideração de "quem é cidadão", e também nas formas de se administrar os conflitos, desde cedo.

É justamente nesse cenário que se inserem os meios autocompositivos de resolução de demandas, centrados na colaboração. Diante da sobredita mudança paradigmática, no entanto, a ideia de competição como forma de sobrevivência, não obstante tenha reinado em diversos momentos do pensamento científico, a exemplo da teoria da darwiniana da evolução, entra em declínio, e a constatação de que o planeta é um sistema vivo e autorregulador, composto de relações inseparáveis e interdependentes, impacta não somente as Ciências Naturais, mas também as interações sociais (CAPRA; LUISI, 2014), entre elas as formas de administração de conflitos. Na esteira de Capra e Luisi,

a evolução não é mais considerada como uma luta competitiva pela existência, mas, em vez disso, é reconhecida como uma dança cooperativa na qual a criatividade e a constante emergência da novidade são as forças propulsoras. E, com a nova ênfase na complexidade, nas redes e nos padrões de organização uma nova ciência da qualidade está lentamente emergindo (CAPRA; LUISI, 2014, p. 14). 


\section{Humanos e \\ Democracia}

Nesse contexto insere-se a mediação, centrada na colaboração, no pensamento que se processa por meios de relações e contextos, de consideração do ambiente interno do conflito e também externo, que alberga situações que impactam sobremaneira a dinâmica conflitiva, servindo ora de combustível ora de oportunidade de solução. Importa, aqui, ressaltar que a mediação foca nas dinâmicas colaborativas, no diálogo, nas narrativas, na busca do entendimento e das considerações dos aspectos subjacentes à demanda, que chamamos, no Direito, de lide sociológica.

Essa via de resolução consensual é uma forma de instaurar a comunicação rompida entre as partes em razão da posição antagônica instituída pela disputa, uma vez que facilita a expressão do dissenso, definindo um veículo que possa administrar a discordância e chegar a um entendimento comunicativo (SPENGLER, 2007, p. 343), buscando-se ganhos mútuos a partir da cooperação e da ideia de que os envolvidos, nesse cenário, não possuem estritamente interesses opostos, mas sim interesses que podem ser coadunados, principalmente em casos de relações continuadas e múltiplos vínculos (AXELROD, 2006).

Segundo Spengler e Lucas (2012, p. 62), a mediação também foca na autonomização dos confrontantes na busca por uma resposta consensuada e compartilhada, com fundamento em estruturas de bases de diálogos transformadores, de práticas comunicativas não violentas, de narrativas e da escuta profunda. Seu principal desafio, portanto, não é resolver o conflito, também "não é gerar relações calorosas, aconchegantes ou uma ordem harmoniosa, mas sim encontrar mecanismos que possibilitem uma convivência comunicativamente pacífica, na qual os indivíduos possam falar e ouvir a parte contrária sem, contudo, perceberem-se como rivais" (SPENGLER, 2012, p. 165). Se é pelo diálogo que surgem as bases do conflito, então o diálogo pode ser a melhor opção para tratar das realidades conflitantes (SPENGLER, 2010, p. 1), reduzindo o potencial de hostilidade, de conflito e agressão. Por isso, o que a mediação busca é o diálogo transformador, aquele que modifica a relação, é a devolução do conflito para as partes, que contribuíram para a espiral do dissenso, é a conscientização acerca da necessidade de se despir dos preconceitos e da postura inflexível para que seja possível olhar para o outro com sensibilidade e disposição para compreendê-lo (SPENGLER; LUCAS, 2012, p. 62).

Reconhece-se, no entanto, que a busca pela colaboração quando estamos em um conflito é empreendimento difícil. Nesse ponto, a questão que se coloca, para fins de reflexão, é justamente como buscar a cooperação entre os envolvidos sem a figura central de uma autoridade, sem que haja imposição. Esse questionamento é levantado por Robert Axelrod, na obra "The Evolution of Cooperation", publicada na década de 80 e reeditada em 2006. Axelrod realizou uma série de experimentos a partir da dinâmica conhecida como "Dilema do Prisioneiro" com pessoas de todo o mundo.

Axelrod objetivou buscar a resposta para a questão: Em um mundo onde qualquer estratégia é possível, onde há tanto egoísmo e onde a cooperação é aparentemente baseada somente na reciprocidade, que condições seriam necessárias para alimentar a cooperação (AXELROD, 2006, p. viii)? Esse questionamento o levou a uma perspectiva evolucionária: a consideração de como a cooperação pode emergir entre as pessoas sem uma autoridade central. 


\section{Democracia}

Humanos e

Após pesquisar sobre a evolução da cooperação em um contexto social, o cientista político percebeu que as descobertas também tinham implicações para a evolução biológica. ${ }^{4}$ Desse modo, abriu suas pesquisas para um campo interdisciplinar, no qual inseriu biólogos, matemáticos, cientistas sociais e também uma audiência mais vasta, interessada em entender as condições que podem estimular a cooperação entre indivíduos, organizações e nações. ${ }^{5}$ Questões afetas às dinâmicas cooperativas, pois, têm sido centrais para diversos campos das ciências: política, social, antropológica, econômica, biológica, etc. E na arena da mediação, ela coloca-se como ponto central.

Os meios consensuais lastreiam-se na aproximação dos envolvidos, no seu engajamento, razão pela qual entendemos que não deve haver imposição coercitiva para sua adoção, mas sim liberdade de escolha. Sem essa liberdade o engajamento colaborativo resta prejudicado, minando a confiança e a reciprocidade. Desse modo, o terceiro facilitador deverá, por meio de técnicas e abordagens apropriadas, estimular a cooperação e o diálogo construtivo, fazendo mais do que uma referência a um procedimento consensual, solidário, de mútua composição, sendo indispensável que traga para o campo da resolução a ideia de alteridade, que diz respeito a uma possibilidade de transformar o conflito e de se deixar transformar por ele, graças à possibilidade assistida de poder nos olhar a partir do olhar do outro, e colocar-se em seu lugar para entendê-lo e a si mesmos (WARAT, 2004b, p. 62). Nos dizeres de Fabiana Marion Spengler e Doglas César Lucas (2012, p. 54):

Tudo isso se dá porque para entabular um diálogo transformador e restabelecer/estabelecer a comunicação rompida ou até então inexistente é preciso se despir dos preconceitos e da postura inflexível e olhar para o outro com um mínimo de sensibilidade e disposição para compreendê-lo, respeitando a sua identidade.

É a alteridade, a outridade, como possibilidade de transformação do conflito (WARAT, 2004b, p. 62). Vistas por essas lentes, a mediação, bem como a justiça restaurativa podem ser consideradas a partir da ética da alteridade: da recuperação do respeito e do reconhecimento da integridade, da dignidade do outro.

Essa mudança de lentes ao olhar para os conflitos traz uma nova concepção dos mesmos. As divergências passam a ser vistas como oportunidades alquímicas, as energias antagônicas como complementares, e o Direito como solidariedade. As velhas lentes que fragmentavam, classificavam e geravam distâncias vão para a lixeira. Começamos a entender que cada homem não é uma mônada isolada, que não são fragmentos sem conexão. Cada um é interdependente e produto forçado das interações. A sociedade é unicamente produto da complexidade desses vínculos (WARAT, 2004b, p. 55).

\footnotetext{
"Yet we also know that cooperation does occur and that our civilization is based upon it. But, in situations where each individual has an incentive to be selfish, how can cooperation ever develop?" (AXELROD, 2006, p. 3). Não obstante, Hobbes, por exemplo, defendeu que não há como haver cooperação sem que houvesse uma forte autoridade, ou seja, um governo forte fazia-se necessário para a estabilização por meio da cooperação. No campo da Biologia, a própria teoria da evolução, de Darwin, é lastreada na competição e na predominância do mais forte. A ideia de competição, portanto, encontrase fortemente arraigada no ethos social, seja por razões biológicas, seja por costumes sociais, o que torna a adoção da colaboração e cooperação mútua tarefa difícil.

Infere-se que essas perspectivas multidisplinares infiltram-se no Direito, como não poderia deixar de ser, considerando a visão sistêmica da vida e, portanto, dos fenômenos não somente naturais (biológicos, físiológicos etc), mas também dos fenômenos sociais.
} 


\section{Democracia}

Humanos e

Esse discurso não é inocente e nem desconsidera o olhar para si mesmo e a autoconsideração. A alteridade e a consideração da dignidade do outro podem coexistir, claro, com a perseguição por interesses individuais. E serão elas que permitirão uma atuação colaborativa na busca por ganhos mútuos, ainda que cada envolvido esteja buscando seus próprios interesses. É imperioso, portanto, forçar essa noção de alteridade, tão relegada pelo mecanicismo cartesiano do século 17 ao século 20 (CAPRA; LUISI, 2004, p. 14) pela modernidade egocêntrica, reducionista, manipuladora, segundo Warat (2004b, p. 145), que ressalta também que a modernidade acabou por diluir o outro em sua alteridade, adotando modelos de egos coletivos ou egos-padrões. Modernidade essa que reforçou, e ainda reforça, uma justiça baseada na punição para os comportamentos disfuncionais.

Assim, a adoção do paradigma sistêmico ou holístico, em contraposição ao individualismo mecanicista da modernidade, pautado em uma racionalidade instrumental, impacta na visão dos meios de resolução de conflitos, trazendo para seu contexto uma visão sistêmica, que não é linear. Vale trazer à baila, nesse ponto, reflexão de Capra e Luisi (2004, p. 15) acerca da visão sistêmica, que deve ser levada em conta quando da análise da mediação:

Uma característica central da visão sistêmica é sua não linearidade: todos os sistemas vivos são redes complexas - isto é, são, em um alto grau, não lineares; e há incontáveis interconexões entre as dimensões biológicas, cognitivas, sociais e ecológicas da vida. Desse modo, um arcabouço conceitual que integre essas muitas dimensões sem dúvida refletirá a não linearidade inerente à vida.

Por conseguinte, se a partida ocorre da premissa da não linearidade inerente à vida, pode-se transpor essa noção para o campo dos conflitos. Eles também seguem essa não linearidade, que pode ser vista e considerada na seara da mediação, principalmente em razão de sua informalidade e dos princípios interdisciplinares a ela inerentes, que possibilitam que considerações acerca das dimensões biológicas, cognitivas, sociais e ecológicas da vida sejam consideradas, permitindo uma solução igualmente sistêmica, que contribua para uma estabilização e até uma pacificação mais duradoura. ${ }^{6}$

Colocadas nessa moldura contemporânea, as finalidades primordiais da mediação são: responsabilizar os conflitantes pelo tratamento do litígio que os une e devolver-lhes o protagonismo na construção criativa das soluções. Essa moldura é fundamentada, em síntese, pela ética da alteridade, pela visão sistêmica que considera a interconexão e interdependência dos fenômenos, naturais e sociais, pelo objetivo de se aparar as arestas e divergências, com vistas à compreensão das emoções reprimidas, pela comunicação direcionada ao entendimento e que atenda aos interesses das partes, e pelo reconhecimento mútuo.

As técnicas utilizadas na mediação, portanto, buscam a substituição da negociação conflitiva, distributiva, pela resolução cooperativa e integradora dos problemas. Por elas, os indivíduos são encorajados a ouvir e a entender os pensamentos e sentimentos uns dos outros, sendo estimulados a gerar opções de ganhos múltiplos e a trabalhar juntos para se chegar a

\footnotetext{
${ }_{6}$ Algumas teorias reforçam a colaboração: é melhor encarar o perigo juntos, pois há força nos números (HICKS, 2011, p. 8). Ou seja, na colaboração há força de superação, mais do que na individualidade. Cientistas têm ancorado essa perspectiva nas funções cerebrais e também os mecanismos de sobrevivência da espécie humana no decorrer dos milênios. Conferir: Hicks (2011); Axelrod (2006); Capra e Luisi (2004); Harari (2007).
} 


\section{Democracia}

Humanos e

uma resposta que seja boa para ambos. A mediação, pois, como espécie do gênero "métodos autocompositivos", é um procedimento democrático porque dissolve os marcos da autoridade, da coerção, determinados por referências normativas que privilegiam a verdade formal e a imposição da solução por um terceiro alheio ao conflito. Ademais, acolhe a desordem e considera o conflito como possibilidade positiva de transformação social (POZZATTI JÚNIOR; KENDRA, 2015, p. 699). É também democrática quanto ao fundamento da relação de um com o outro, apostando na forma compartilhada e consensual, que tenha por base o diálogo inclusivo e fraterno. E é nessa moldura mais ampla, de transição paradigmática, que se coloca a mediação escolar, como subespécie da mediação.

No contexto específico da escola, Alvaro Chrispino et al. (2019, p. 513) defendem que a mediação escolar é uma forma de "organizar comunidades escolares em torno de interesses comuns, promovendo a convivência harmoniosa baseada no respeito mútuo e na cooperação - valores fundamentais da cultura de paz". Esse método pacífico de resolução de conflito, se inserido nas escolas, constitui lócus de escuta, de equacionamento de diferenças, permitindo não somente a consideração dos contextos subjacentes aos comportamentos dissonantes, como também oportunidades para que os jovens desenvolvam habilidades sociais, emocionais e cognitivas, promovendo, por outro lado, o crescimento moral, a partir da valorização do outro e de si mesmo e do reconhecimento mútuo. Esse caráter pedagógico da mediação é ressaltado por Bush e Folger, sendo, inclusive a tônica da Escola Transformativa (1994).

Se utilizada nos conflitos escolares, a mediação pode ser instrumento de desenvolvimento de competências colaborativas por parte dos alunos, dos discentes, dos administradores e dos colaboradores e demais envolvidos no contexto escolar, promovendo novo olhar para dinâmicas que retroalimentam espirais destrutivas de disputas e de violência e propondo diferentes formas de se lidar com situações conflitivas, a partir de uma abordagem dialógica, direcionada à construção do consenso a partir da utilização de técnicas que estimulem o fortalecimento da empatia, da responsabilização, do reconhecimento mútuo e do empoderamento.

As escolas, em sua maioria, ainda trabalham sob o viés retributivo, verticalizado, baseando-se num saber que tem força de lei, "um sistema de valor e de ação que se apresenta como a expressão de uma verdade absoluta" (CHRISPINO et al., 2019, p. 518) explicitada em regras de conduta que, se descumpridas, acarretam sanções. A regra, portanto, é a punição, baseada em uma justiça retributiva, não havendo espaço para a escuta das histórias que levam às condutas dissonantes. $E$ a punição não garante, por si só, a conscientização e a mudança de comportamento, a responsabilização e a real noção acerca das consequências de um comportamento danoso. Sozinha ela exclui, envergonha, aliena e não necessariamente considera as necessidades de quem sofreu com o ato danoso e de quem o praticou.

A punição mais esgarça o tecido social, não contribuindo para sua recomposição e para a tomada de consciência, amadurecimento, autorresponsabilização de quem a sofre. Em se tratando de jovens, principalmente, ela não ensina, podendo causar maior revolta e incrementar mais ainda espirais de exclusão e de violência.

Ante essas considerações é que a mediação, juntamente com a justiça restaurativa no ambiente escolar, mostram-se como vias mais adequadas, eis que visam, justamente, a contribuir para a superação do paradigma punitivo e surdo aos verdadeiros anseios dos envolvidos e dos afetados, e para o fortalecimento da alteridade, da restauração e da transformação 


\section{Democracia}

Humanos e

das relações. E aqui buscaremos mostrar que a visão tradicional, calcada no binômio prêmio-castigo, não produz mudanças estruturais e transformações que propiciem verdadeiras mudanças positivas de comportamentos, perdendo-se oportunidades de construção de modelos cooperativos, participativos e inclusivos, que auxiliam na resolução pacífica das controvérsias, contribuindo para a formação de cidadãos conscientes de seu poder de autodeterminação e de replicadores da filosofia da mediação.

O ambiente escolar, portanto, é ideal para se "capacitar as pessoas a conviver com respeito, interdependência, responsabilidade e cooperação, que são os princípios básicos da cultura de paz e também da mediação" (CHRISPINO et al., 2019, p. 527). Capacitando os jovens e ensinando-lhes novas formas de lidar com as diferenças e com o conflito de interesses estaremos contribuindo para a tão almejada mudança cultural, de uma cultura combativa e litigante para outra mais cooperativa, sensível às diferenças, inclusiva e pacífica.

Se aqui caminhamos na trilha da defesa da mediação como método mais adequado à resolução de conflitos escolares, mister se faz trazer um conceito de mediação, mesmo já tendo sido objeto de delimitação conceitual por diplomas legais. Aqui, consideramos mediação como uma forma de se resolver disputas (ou de tratar conflitos), facilitada por um terceiro imparcial, que auxilia as pessoas envolvidas a alcançar um entendimento, a partir da escuta dos interesses subjacentes, da possibilidade de expressão de emoções e da escuta das histórias que se escondem por trás das posições assumidas. A mediação é desenhada para que todos os envolvidos sintam-se tratados com respeito, com consideração, na medida em que deve se desenvolver em um ambiente seguro, confidencial, imparcial, acolhedor. Na mediação, as partes devem ser tratadas como iguais, possuidoras da mesma dignidade, com igual oportunidade de fala e escuta, deixando-se sempre claro que são elas que melhor podem construir a solução para seu conflito. O mediador, como catalisador das relações, deve ser responsável pelo processo, mas não pelo resultado, que é produto das interações construtivas entre as partes. O procedimento, portanto, deve ser claro, justo e respeitoso. Somente observando-se esses pressupostos os indivíduos passam a sentir confiança no espaço e no mediador.

Trazemos também um outro conceito, segundo o qual mediação constitui-se em um "processo estruturado de facilitação da comunicação entre os opositores, visando reduzir as tensões emocionais para que possam criar cooperativamente alternativas de solução que sejam mutuamente satisfatórias, justas e duradouras" (CHRISPINO et al., 2019, p. 527).

Para que haja colaboração, porém, a confiança é fundamental, eis que, quando um indivíduo provoca um dano, quando fere outro indivíduo, há uma ruptura da confiança e da segurança necessárias à estabilização das relações e à disposição para a escuta autêntica. Um passo importante, pois, é trabalhar para se restabelecer a confiança, ou desconstruir a desconfiança entre as partes envolvidas. O papel do mediador, portanto, é assegurar um espaço para que a confiança mútua possa ser trabalhada, reconstruída na melhor medida possível. Trabalho árduo esse, mas necessário para que o diálogo possa ocorrer de forma respeitosa e para que cada qual reconheça sua responsabilidade em razão de suas condutas.

Assim, partindo dessas colocações, passamos à análise de alguns exemplos de conflitos escolares, colhidos a partir de pesquisas de campo, para fins de fundamentar a posição aqui adotada, de defesa da mediação escolar, como instrumento pedagógico para a formação de jovens conscientes de seu papel na construção da cultura de paz e de replicadores da filosofia da mediação. 


\section{Democracia}

Humanos e

\section{ALGUNS CONFLITOS ESCOLARES EM PERSPECTIVA EMPÍRICA}

A oportunidade de pesquisar formas de administração de conflitos escolares surgiu quando tivemos contato com o seguinte caso de mediação escolar, envolvendo disputa entre duas estudantes de uma escola particular da cidade de Petrópolis-RJ. Esse caso é particularmente significativo e paradigmático, razão pela qual temos feito referência a ele como um ponto de partida em nossas reflexões sobre o tema, tratando-se do relato de uma experiência prática.

Ao sermos chamados para intervir no caso, mediar o conflito, havia uma rixa entre as duas estudantes perpetuada por meses, que por pouco não descambou em agressões físicas, revelando-se um exemplo de incremento de espiral destrutiva, que se iniciou com um dissenso. Como uma das estudantes era um pouco mais velha e visivelmente mais alta e forte do que a sua rival, esta última ficou intimidada, passando a apresentar queda de rendimento escolar. Sua mãe também relatou que a filha, geralmente uma estudante assídua e interessada, passou a inventar desculpas para não ir à escola, queixando-se com frequência de dores de cabeça e enjoos como justificativas para permanecer em casa.

A situação poderia ser encaixada no conceito de bullying que, segundo Teixeira (2011), pode ser definido como o comportamento agressivo entre estudantes. São atos de agressão física, verbal, moral ou psicológica que ocorrem de modo repetitivo, sem motivação evidente, praticados por um ou vários estudantes contra outro indivíduo, em uma relação desigual de poder, normalmente dentro da escola. Ocorre principalmente em sala de aula e no horário do recreio (ALMEIDA, 2011).

Preocupada, a mãe procurou os dirigentes da escola e ficou sabendo que a desavença teria sido causada por um comentário feito durante um intervalo a respeito do interesse comum por um rapaz, a partir do qual as estudantes, antes boas colegas, tornaram-se rivais. Os pais das estudantes foram chamados à escola e, juntamente com os seus dirigentes e um mediador, construíram uma solução pacífica entre elas. As reuniões, em um total de três, realizadas durante aproximadamente duas semanas, culminaram com o compromisso de que cada uma, dali por diante, respeitaria o espaço da outra, evitando novas agressões. O problema foi contornado.

Uma das mães admitiu, ao final da última reunião, que pensara em transferir a filha para outro estabelecimento e que já contratara um advogado para ajuizar ação contra a escola e os pais da aluna desafeta de sua filha, pois não enxergava outra solução para o problema, mas ficou satisfeita com o resultado da mediação e desistiu de intentar a ação. A despeito disso, seu relato deixou evidenciado que o seu primeiro impulso apontou para via judicial como a solução para a questão que tanto afligia sua filha.

Nessa situação observada, um método consensual e extrajudicial, conduzido no próprio ambiente escolar, com a intervenção de terceiros, mediante o emprego de técnicas de mediação (BRAGA NETO, 2012), conseguiu evitar o ajuizamento de uma ação que, possivelmente, poderia ser muito mais prejudicial (custosa e demorada) para os envolvidos, além do que, por ser o procedimento adjudicatório acentuadamente polarizado e adversarial, ele acabaria esgarçando mais ainda as relações, por levar sempre a uma solução de soma-zero, ou perde-ganha, o que gera mais insatisfação e até revolta. Segundo as dirigentes da escola, essa forma 


\section{Democracia}

Humanos e

de tratar o conflito apresentou um aspecto pedagógico, propondo modificação de comportamentos e de percepções, aprendizado quanto a métodos mais pacíficos de resolução das contendas e restabelecendo as condições para uma convivência mais pacífica entre as estudantes, sem necessidade de providências mais severas. Essas são algumas das características da mediação, enaltecidas por autores como Warat (2004b; 2011), Azevedo (2012) e Vezulla (2013).

Em contato com estudantes de Ensino Médio que participam como Jovens Talentos em nosso grupo de pesquisa em Petrópolis, RJ, no entanto, percebemos que as iniciativas que envolvem a abordagem e tratamento do conflito em sede escolar, antes de se tornarem ações judiciais, não são tão comuns. Geralmente, talvez por falta de treinamento/capacitação adequada para esse tipo de intervenção, ou até de consciência acerca de sua potencialidade gerativa de mudanças de conduta, a postura da escola e seus dirigentes mostra-se mais como se fossem espectadores, não enxergando, a si próprios, como administradores ou solucionadores de conflitos. Evita-se o enfrentamento e, até mesmo, a visibilidade do conflito (FILPO; SAMPAIO; PEREIRA, 2017), como se a evitação fosse, por si só, uma forma de "resolver" a controvérsia com o passar do tempo. Isso ocorre de formas variadas, tais como: alegar que conflitos não ocorrem entre os seus estudantes, ou delegar o tratamento desses conflitos a outras entidades, como o Conselho Tutelar e a Ronda Escolar, ligada à guarda municipal (no caso de Petrópolis, RJ).

Ao ser entrevistada por uma de nossas alunas, a diretora de uma escola particular da cidade informou que deveríamos ir a outra escola, preferencialmente uma escola pública, uma vez que naquela escola que ela dirige "não tem essas coisas de conflito não" (cf. FILPO; SAMPAIO; PEREIRA, 2017). Essa postura mostra a frequente atitude de muitos gestores em negar a existência de controvérsias, como se elas não fossem naturais e inerentes a qualquer relação humana. Com isso, perdem-se oportunidades de gerir os conflitos de forma construtiva, contribuindo para mudanças organizacionais e nas inter-relações.

Por outro lado, uma diretora de escola pública revelou não saber muito bem como lidar com casos de conflitos surgidos na escola. Isso depende, em alguns casos, do que se trata. Por exemplo, em casos de furto de celulares - os quais, segundo relatos, hoje são comuns - geralmente um trabalho de conversa, de convencimento, feito pelas professoras, traz bons resultados com a devolução do aparelho - segundo nossa entrevistada. Há outros casos, contudo, principalmente incluindo "alunos-problema" (categoria que apareceu no trabalho de campo), em que a solução costuma ser o encaminhamento do caso ao Conselho Tutelar (FILPO; SAMPAIO; PEREIRA, 2017).

A diretora deixou transparecer que não recebe formação e não está preparada para a resolução de conflitos na escola. Parecia ter receio das consequências prejudiciais para a sua carreira, caso venha a interferir de forma equivocada em um conflito, preferindo uma postura mais passiva em muitos casos e que, nesse contexto, parece ser mais segura e previsível, que é antiga ideia de que a retribuição "resolve".

Mendonça Pinto (2014, p. 94) em etnografia que incluiu observações em escolas de Seropédica-RJ, também percebeu uma ausência de instâncias escolares para resolução de conflitos, que inclusive apareceu na fala de alguns estudantes entrevistados: 


\section{Democracia}

Humanos e

Não há (interferência da escola), na verdade, quando isso acontece, aconteceu "morreu" ali ou até mesmo não morreu, fica aquele professor olhando de rabo de olho pro aluno, ninguém interfere não, nenhum tipo de aluno - rapaz do 10 ano (.

Por outro lado, o número e a diversidade de conflitos no espaço escolar tem se mostrado muito significativo. Leitura preliminar realizada a esse respeito revelou um dado interessante: tem se tornado cada vez mais comum, no Brasil, que conflitos corriqueiros entre estudantes, mesmo de pouca idade, formem uma espiral, tornando-se muito graves, envolvendo agressões físicas e outras violações de direitos que, não raro, chegam às barras do Judiciário. Aguinsky et al. (2015) observaram que, na ocasião de sua pesquisa, verificava-se "a ampliação da judicialização de conflitos que envolvem situações de baixo potencial ofensivo, como conflitos nas escolas, que não raro podem resultar na imposição de medidas socioeducativas".

Em se tratando do fenômeno da judicialização de conflitos escolares, segundo as mesmas autoras, nem sempre a dimensão educativa irá prevalecer, havendo ainda que se levar em consideração a exposição dos adolescentes a constrangimentos e violências institucionais decorrentes de uma eventual inserção no Sistema de Justiça e Segurança. Elas anotam que os conflitos escolares adentram o Sistema de Justiça Juvenil, e o seu tratamento exigiria "a articulação do Sistema de Garantia de Direitos da Criança e do Adolescente, no que se inclui Judiciário, Ministério Público, Delegacias de Polícia, Poder Executivo Municipal, Escolas e Conselhos de Direito e demais políticas públicas".

A despeito dessas percepções, as observações e entrevistas feitas até o momento, no município de Petrópolis-RJ (pesquisa realizada com recursos do CNPq - Edital Universal 2016), sugerem que, em geral, a mediação ou outros métodos de intervenção consensual dos conflitos não são identificados pelos atores do campo como uma via que possa ser acionada para o tratamento de conflitos surgidos na escola. Pelo contrário, na maioria dos casos examinados optou-se por submeter o conflito diretamente ao sistema de Justiça, muitas vezes por meio do acionamento da autoridade policial, ou da Guarda Municipal, responsável pelo serviço denominado "Ronda Escolar". Não foi observado ser comum, nesses casos examinados, ocorrer uma tentativa de composição amigável anterior, ainda em sede escolar.

A não adoção das práticas consensuais no âmbito escolar deve-se a uma diversidade de fatores, particulares a cada instituição e contexto comunitário em que inserida. Um fator comum, porém, que pode ser constatado é a falta de conhecimento por parte de muitos gestores, demandando trabalhos prévios de sensibilização, a ausência de treinamento da diretoria, de professores e de funcionários, a inexistência de interlocução das escolas com ambientes externos, tendo como objetivo ampliar o caráter pedagógico de ações propostas bem como possibilitando maior diálogo entre a escola, os familiares dos alunos, a comunidade, outras instituições educacionais e o poder público. Esse diálogo permite que profissionais de outras instituições e áreas promovam eventos pedagógicos que contribuam para o conhecimento, a conscientização e o aprendizado de temas afetos a métodos pacíficos de resolução de conflitos, de prevenção de bullying e de adiç̧ão, além da discussão de temas específicos da escola. Trata-se, portanto, de uma maior inserção da escola na comunidade, fortalecendo o senso de pertencimento e de contextualização vivencial do ensino.

Assim sendo, tomando-se por base esses poucos exemplos trazidos, podemos inferir que a política nacional de tratamento adequado de conflitos de interesse, por ser recen- 


\section{Democracia}

Humanos e

te e por estar se voltando com especial interesse para as questões judiciais, considerando o CPC/2015, as Resoluções 125/2010 e 225/2016, ambas do CNJ, ainda há um largo campo inexplorado no tocante à utilização da mediação extrajudicial, que pode ter lugar em diferentes espaços: nos escritórios dos advogados, nas associações de bairros, nos condomínios, nas agremiações - e em especial, no caso deste paper, nas escolas. Essa seria, em nosso entendimento, um desdobramento necessário dessa política pública.

Esse fenômeno mostra que, no Brasil, o movimento da ADR (Alternative Dispute Resolution), como são chamados os meios consensuais, teve seu principal impulso iniciado pelo Estado (poder Judiciário), para então se espalhar pelas comunidades, escolas, círculos de convivência. $E$, atualmente, assistimos a um processo de desterritorialização das resoluções das disputas e sua apropriação por lócus mais informais e pela própria sociedade. São movimentos consectários da crescente percepção de que o campo da resolução de conflitos, em verdade, é um solo fértil para o desenvolvimento de competências e habilidades sociais e de incremento de uma cidadania mais participativa e consciente acerca dos direitos e deveres que revestem a condição de ser cidadão de uma sociedade plural e democrática.

\section{EDUCAR PARA A MEDIAÇÃO, É POSSÍVEL?}

Autores como Warat (2004b) e Vezulla (2013) ressaltam o potencial educativo e transformador da mediação. Para esses autores, a formação para a mediação, ou antes, a prática da mediação, é capaz de exercitar a alteridade e preparar as pessoas para viverem melhor com os outros. Para Warat, inclusive, a Justiça, no Brasil, tem de ser "pedagógica e terapêutica", eis que os cidadãos precisam, antes de tudo, resolver a questão de sua própria identidade para, então, ter a consciência do que é ser cidadão. E a mediação auxilia a aprendizagem acerca dos sentidos e das práticas cotidianas da cidadania. "Este é o trabalho da mediação preventiva" (WARAT, 2010, p. 4). Trata-se, pois, de uma mudança de postura ante os conflitos, que o exercício da mediação propicia, fortalecendo seu caráter pedagógico.

Ainda, para Bentes e Monnerat (2017), o sentido de mediação delineado por Warat compreende a forma de resolução dos conflitos por meio do consenso alcançado entre as partes envolvidas, o que levaria à formação de cidadãos verdadeiramente comprometidos com os direitos humanos e com o ideal de construção de uma sociedade justa e fraterna, na medida em que as partes conflitantes chegariam a reconhecer a outra parte e os seus direitos correspondentes. A concepção de mediação não se limitaria, assim, à composição dos conflitos, peculiar da esfera extrajudicial, mas se expandiria por todas as situações caracterizadas pela extrema vulnerabilidade social, que exigem a intermediação e ações efetivas na direção de facilitar o acesso das pessoas fragilizadas aos órgãos competentes para a promoção dos direitos humanos e do exercício da cidadania.

Nessa medida, trabalhar com mediação de conflitos da escola poderia produzir resultados em duas vertentes: tanto na oferta de meio mais adequado para tratar dos conflitos surgidos no espaço escolar como na preparação de pessoas para promover o diálogo e o consenso. Tudo de forma consentânea com a política pública que nos interessa neste paper.

Não obstante, alguns autores vêm levantando questionamentos sobre a efetividade dos meios consensuais - como a mediação e a conciliação - como formas institucionalizadas de administração de conflitos no Brasil, posto que parece existir grande dificuldade na sua as- 


\section{Democracia}

Humanos e

similação no plano empírico. Tal dificuldade, ou mesmo indiferença, parece existir tanto na escola como em outros espaços, alguns deles no próprio poder Judiciário.

Por exemplo, pesquisa de campo conduzida no Estado do Rio de Janeiro entre 2010 e 2013 constatou dificuldades nas primeiras experiências com o emprego da mediação pelo Tribunal de Justiça do Estado do Rio (FILPO, 2016). Uma das dificuldades identificadas foi a reduzida adesão dos juízes à mediação, pois muitos acreditavam que não surtiria efeitos concretos e poderia acabar alongando demasiadamente o processo. Os defensores da mediação, por sua vez, argumentavam que essa percepção era devida ao desconhecimento generalizado sobre as práticas mediativas, o que poderia ser superado com o passar do tempo, por meio de atividades de divulgação (das qualidades atribuídas à mediação) e capacitação (de profissionais para efetivá-la e difundi-la).

Nicácio (2012, p. 57), por sua vez, relata experiências vivenciadas no Brasil e na França, onde foram disponibilizados serviços de mediação em diferentes espaços, sendo mais tarde verificado que essas iniciativas não contaram com a adesão da população como esperavam os seus entusiastas. Essa autora (NICÁCIO, 2012, p. 57), após refletir sobre essa questão e com base na obra de pesquisadores franceses, formulou uma possível explicação para esse fenômeno, sustentando que

a) tais experiências [com a mediação] não intervêm suficientemente cedo no processo de desenvolvimento, apreensão e consciência jurídica de cada cidadão, mas somente quando suas concepções sobre direito ou justiça já se encontram extremamente consolidadas e por isso difíceis de serem alteradas e que b) consequentemente, uma mudança substantiva em determinada cultura jurídica implica trabalhar os pilares da socialização jurídica dos indivíduos desde a mais tenra infância ou por meio de organizações comunitárias que tenham legitimidade para conduzir discussões e cursos com e para moradores do local.

Tomando como uma hipótese essa dificuldade de absorção, por motivos culturais, e colocando-a em outros termos, pode-se supor que as iniciativas voltadas para o emprego da mediação, como alternativa à prestação jurisdicional convencional, tendem a ser mais bem-sucedidas quando os usuários são familiarizados com esse método desde muito jovens (em contato com experiências levadas a efeito na escola e na comunidade). Quando isso não acontece a dificuldade é maior, pois a concepção que cada um tem sobre o direito e a justiça não são tão fáceis de modificar, eis que arraigada em processos históricos de formação da sociedade, responsáveis pela construção de uma sensibilidade jurídica (GEERTZ, 2009) atrelada à ideia da justiça como produto da atividade estatal ajudicatória, que reduz a solução do conflito àquela imposta pela autoridade judicial. Aparentemente trata-se de um processo que demanda tempo e a conjugação de outros fatores para além da lei. Estamos nos referindo à cultura.

Segundo uma teoria antropológica bastante disseminada, a cultura é algo vivo, dinâmico, podendo modificar-se com o passar do tempo. Laraia (1986, p. 98-99), em um texto bastante esclarecedor e de grande repercussão sobre as formas "como opera a cultura", em perspectiva antropológica, fornece alguns exemplos simples e interessantes a respeito das mudanças culturais a que qualquer sociedade está sempre sujeita. As formas de vestir, por exemplo. No caso brasileiro, o autor compara as vestimentas usadas por homens e mulheres do Rio de Janeiro no início do século passado com as atuais. E conclui que, assim como mu- 


\section{Democracia}

Humanos e

dam as formas de vestir, muitas outras coisas mudam, no espaço social, com o passar do tempo. Assim também podemos pensar que uma certa percepção sobre Direito e Justiça podem se modificar, mas para tanto é necessário começar da base, ou seja, da educação dos jovens e crianças para a adoção de novas práticas, comportamentos e percepções sobre a forma de se fazer justiça.

Esse interessante relato leva-nos a concluir que mudanças sensíveis no que diz respeito às formas preferenciais para a administração de conflitos demandam tempo, assim como, na teoria antropológica acima referida, a forma de vestir modificou-se e continua se modificando com o passar dos anos. A comparação é válida, uma vez que o Direito é um saber local, uma visão de mundo, intrinsecamente ligado à cultura de cada povo (GEERTZ, 2009), tanto quanto a forma de vestir; as crenças compartilhadas; determinados rituais e hábitos alimentares, entre outros. A forma como enxergamos a atividade de solução de conflitos e a aplicação do Direito também fazem parte do acervo cultural transmitido às gerações seguintes, daí a importância de pensar em uma educação para a mediação.

\section{CONSIDERAÇÕES FINAIS}

$\mathrm{Na}$ experiência brasileira a medição somente há pouco tempo vem sendo disponibilizada à sociedade, tendo como marco mais relevante a Resolução 125/2010 do CNJ, que instituiu os Tribunais como polos difusores das soluções consensuais dos conflitos de interesse. Trata-se, portanto, de uma política pública disparada, no Brasil, por iniciativa do poder Judiciário, operando-se "de cima para baixo", ou seja, do Estado para a sociedade. Embora, contudo, o Judiciário tenha tomado a dianteira nesse movimento, é evidente que não pode monopolizar os meios de solução de conflitos, sobretudo os consensuais, isso porque ele detém o monopólio da jurisdição, de dizer o Direito no caso concreto, mas não de solucionar o conflito.

Posteriormente, iniciativas análogas foram observadas no Código de Processo Civil (Lei 13.105/2015) e na Lei de Mediação (Lei 13.140/2015). São diplomas normativos que ainda dependem de serem testados ao máximo das suas respectivas potencialidades, no campo da solução consensual de conflitos, mas que refletem uma tomada de posição do legislador: soluções consensuais podem ser buscadas, em muitos casos, como alternativas ao modelo judiciário de administração de conflitos.

Essas mudanças no cenário normativo refletem uma tendência mais ampla: uma transformação paradigmática - de um paradigma ancorado em uma visão mecanicista, individualista, adversarial e calcado na competição - para um paradigma mais holístico, ecológico, que tem na ideia de interconexão seu epicentro, e na cooperação e no respeito valores que devem permear todas as relações, sejam entre indivíduos, comunidades, Estados-nações, entre si, e também com o próprio planeta. E os meios consensuais, podemos destacar, são produtos desse olhar mais holístico para o ser humano e suas relações. É necessário, todavia, trazer à consciência dos cidadãos, e da sociedade em geral, a importância de sua adoção, como uma pedagogia para o tratamento de conflitos simples e complexos, como oportunidade de aprendizado e construção de uma nova cultura, mais pacífica.

Ao que se percebe até o momento, no entanto, os esforços empreendidos pelo legislador não parecem suficientes para garantir uma preferência pelas formas consensuais de solução de conflitos no Brasil, quer em sede judicial, quer em espaços extrajudiciais (a escola 


\section{Democracia}

Humanos e

seria um deles). Ou mesmo para modificar comportamentos e sentimentos sobre o Direito e o poder Judiciário. Pode ser que isso demande tempo e a socialização em outros modos de administração de conflitos. Neste texto sugerimos pensar em formas de educar pela mediação e para a mediação.

Isso posto, sob a ótica da pesquisa aqui considerada, a escola não parece ter sido eleita como um espaço preferencial para o tratamento dos conflitos que surgem dentro ou a partir dela, nem há notícia até o momento de programas de capacitação de mediadores escolares em larga escala. Logo, abre-se aqui uma janela de oportunidades, pensando a escola como um espaço adequado para a formação de estudantes que poderão desenvolver habilidades e competências para, no futuro, lidar de forma mais cooperativa diante dos conflitos e dos mecanismos disponíveis para solucioná-los, construindo um novo paradigma educacional que contribui para a formação de uma cidadania mais responsável e preocupada com o todo - sociedade e planeta. Transformações essas que impactam, inevitável e positivamente, no arrefecimento de espirais de violência e no fortalecimento da cultura de paz.

\section{REFERÊNCIAS}

AGUINSKY, Beatriz Gerhenson et al. Judicialização dos conflitos escolares: desafios para a materialização dos princípios do Sinase. Disponível em: http://ebooks.pucrs.br/edipucrs/anais/serpinf/2014/assets/21.pdf. Acesso em: 1a abr. 2015

ALMEIDA, Carlos Alberto Lima de. Bullying na perspectiva da disciplina escolar e dos direitos da criança e do adolescente. Participação em Debate, Fórum Permanente de Direito Educacional, 2011.

AZEVEDO, André Gomma de (org.). Manual de mediação judicial. Brasília, DF: Ministério da Justiça e Programa das Nações Unidas para o Desenvolvimento, 2012.

AXELROD, Robert. The Evolution of Cooperation. Cambridge: Basic Books, 2006.

BENTES, Hilda Helena Soares Bentes; MONNERAT, Diego Machado. O ofício do mediador na perspectiva controversial: a arte de construir a autonomia e o sujeito de direito. Revista Interdisciplinar de Direitos Humanos, v. 5, n. 1, p. 149-166, jan./jun. 2017.

BRAGA NETO, Adolfo. Mediação de conflitos: conceito e técnicas. In: LORENCINI, Marco Antônio Garcia Lopes; SALLES, Carlos Alberto de; SILVA, Paulo Eduardo Alves da (coord.). Negociação, mediação e arbitragem: curso básico para programas de Graduação em Direito. Rio de Janeiro: Forense, 2012. p. 103-125.

BRASIL. Conselho Nacional de Justiça. Resolução no 125/2010. 2010. Disponível em: http://cnj.jus.br/programas-e-acoes/conciliacao-mediacao/legislacao. Acesso em: 2 mar. 2015.

BRASIL. Conselho Nacional de Justiça. Resolução no 125/2010. Resolução no 225, de 31 de maio de 2016. 2016. Disponível em: http://www.cnj.jus.br/atos-normativos?documento=2289. Acesso em: 16 nov. 2018.

BRASIL. Lei no 13.105/2015 - Código de Processo Civil. 2015a. Disponível em: http://www.planalto.gov.br/ccivil_03/_Ato2015-2018/2015/Lei/L13105.htm. Acesso em: 18 mar. 2015.

BRASIL. Lei no 13.140/2015. Dispõe sobre a mediação entre particulares como meio de solução de controvérsias e sobre a autocomposição de conflitos no âmbito da administração pública. 2015b. Disponível em: http://www. planalto.gov.br/ccivil_03/_ato2015-2018/2015/lei//13140.htm. Acesso em: 10 maio 2018.

BUSH, Baruch; FOLGER, Joseph. The Promise of Mediation: The Transformative Approach to Conflict. Colorado: Colorado University, 1994.

CAPRA, Fritjof; LUISI, Pier Luigi. A visão sistêmica da vida: uma concepção unificada e suas implicações filosóficas, políticas, sociais e econômicas. São Paulo: Cultrix, 2004.

CHRISPINO, Alvaro et al. Mediação escolar: uma via para a convivência pacífica. In: ALMEIDA, Tania; PELAJO, Samantha; JONATHAN, Eva (coord.). Mediação de conflitos: para iniciantes, praticantes e docentes. Salvador: JusPodivium, 2019.

CHRISPINO, Alvaro; CHRISPINO, Raquel. Políticas educacionais de redução da violência: mediação do conflito escolar. São Paulo: Editora Biruta, 2002. 


\section{Democracia}

Humanos e

CHRISPINO, Alvaro. Gestão do conflito escolar: da classificação dos conflitos aos modelos de mediação. Ensaio: Aval. Pol. Públ. Educ., Rio de Janeiro, v. 15, n. 54, p. 11-28, jan./mar. 2007. Disponível em: http://www.scielo.br/ pdf/ensaio/v15n54/a02v1554.pdf. Acesso em: 3 fev. 2018.

FILPO, Klever Paulo Leal. Mediação judicial: discursos e práticas. Rio de Janeiro: Mauad X; Faperj, 2016.

FILPO, Klever Paulo Leal; SAMPAIO, Beatriz Magrani; PEREIRA, Laura Macedo Diniz Marques. Estudo de casos de judicialização e mediação de conflitos escolares no município de Petrópolis. ENCONTRO NACIONAL SOBRE O ENSINO DE SOCIOLOGIA BÁSICA - ENESEB, 5., 2017. Rio de Janeiro. Anais [...]. 2017. Brasília, DF: UnB. Disponível em: http://www.aconteceeventos.com.br/Anais\%20ENESEB/resumos/PPT-eposter-trab-aceito-0175-1.pdf. Acesso em: 10 maio 2018.

GEERTZ, Clifford. Obras e Vidas: o Antropólogo como Autor. Rio de Janeiro: UFRJ, 2009.

GIANEZINI, Kelly et al. Políticas públicas: definições, processos e constructos no século XXI. Revista de Políticas Públicas, v. 21, n. 2, 2017. Disponível em: http://www.periodicoseletronicos.ufma.br/index.php/rppublica/article/view/8262. Acesso em: 7 maio 2018.

GROSSI, Patrícia Krieger; AGUINSKY, Beatriz Gerhenson; SANTOS, Andréia Mendes dos. Justiça restaurativa nas escolas de Porto Alegre: desafios e perspectivas. Disponível em: http://justica21.org.br/arquivos/bib_272.pdf. Acesso em: 12 mar. 2015.

HARARI, Youval Noah. Uma breve história da humanidade. Trad. Janaína Marcantonio. Porto Alegre: L\&PM Editores, 2007.

HICKS, Donna. Dignity: Its Essential Role in Resolving Conflict. New Haven: Yale University Press, 2011.

LARAIA, Roque de Barros. Cultura: um conceito antropológico. Rio de Janeiro: Jorge Zahar Editor, 1986.

LEDERACH, John Paul. Transformação de conflitos. São Paulo: Palas Athena, 2012.

MALINOWSKI, Bronislaw. Argonautas do Pacífico Ocidental: um relato do empreendimento e da aventura dos nativos nos arquipélagos da Nova Guiné Melanésia. São Paulo: Abril Cultural, 1978.

MARTín, Nuria Belloso. A Mediação. In: SPENGLER, Fabiana Marion; LUCAS, Doglas Cesar (org.). Justiça restaurativa e mediação - políticas públicas no tratamento dos conflitos sociais. ljuí: Editora Unijuí, 2011.

MELLO, Kátia Sento Sé; BAPTISTA, Bárbara Gomes Lupetti. Mediação e conciliação no Judiciário: dilemas e significados. Dilemas - Revista de Estudos de Conflitos e Controle Social, Rio de Janeiro: IFCS/UFRJ, v. 4, n. 1, jan./mar. 2011.

MENDONÇA PINTO, Nalayne. Juventude, conflitos e consensos: estudo de caso em duas escolas. In: GUEDES, Simoni Lahud; CIPINIUK, Tatiana Arnaud (org.). Abordagens etnográficas sobre educação. Rio de Janeiro: Alternativa; Faperj, 2014. p. 83-96.

NICÁCIO, Camila Silva. A mediação frente à reconfiguração do ensino e da prática do direito: desafios e impasses à socialização jurídica. In: BENTES, Hilda Helena Soares; SALLES, Sérgio de Souza. Mediação e educação em direitos humanos. Rio de Janeiro: Lumen Juris, 2012.

NUNES, Thais Borzino Cordeiro. A conciliação nas ações fazendárias: perspectivas teóricas e obstáculos empíricos para a sua efetiva implementação. 2014. Monografia (Graduação em Direito) - Universidade Católica de Petrópolis, Faculdade de Direito, Petrópolis, 2014.

POZZATTI JÚNIOR, Ademar; KENDRA, Veridiana. Do conflito ao consenso: a mediação e o seu papel de democratizar o direito. Revista Eletrônica do Curso de Direito da UFSM, v. 10, n. 10, 2015. Disponível em: www.ufsm.br/ redevistadireito

SIMIÃO, Daniel et al. Sentidos de justiça e reconhecimento em formas extrajudiciais de resolução de conflitos em Belo Horizonte. In: KANT DE LIMA, Roberto; EILBAUM, Lucía; PIRES, Lenin (org.). Conflitos, direitos e moralidades em perspectiva comparada. Rio de Janeiro: Garamond, 2010.

SPENGLER, Fabiana Marion. Fundamentos políticos da mediação comunitária. ljuí: Editora Unijuí, 2012a.

SPENGLER, Fabiana Marion. Retalhos de mediação. Santa Cruz do Sul: Essere Nel Mondo, 2012b.

SPENGLER, Fabiana Marion. A mediação como estratégia para despolarizar a comunicação. Disponível em: http://fabianamarionspengler.blogspot.com/2010/08/mediacao-como-estrategia-para.html. Acesso em: 7 fev. 2019.

SPENGLER, Fabiana Marion. O Estado-jurisdição em crise e a instituição do consenso: por uma outra cultura no tratamento de conflitos. 2007. 476 f. Tese (Doutorado) - Programa de Pós-Graduação em Direito da Universidade do Vale dos Sinos, São Leopoldo, 2007. Disponível em: http://www.dominiopublico.gov.br/download/teste/arqs/cp126648. pdf. Acesso em: 10 jun. 2017.

SPENGLER, Fabiana Marion; LUCAS, Doglas César. Identidade, alteridade e mediação: por uma comunicação inclusiva das diferenças. Direitos Culturais, Santo Ângelo, v. 7, n. 12, p. 53-70, jan./jun. 2012. 


\section{Humanos e \\ Democracia}

TEIXEIRA, Gustavo. Manual antibullying para pais, alunos e professores. Rio de Janeiro: Best Seller, 2011.

VEZULLA, Juan Carlos. A mediação para uma análise da abordagem dos conflitos à luz dos direitos humanos, o acesso à justiça e o respeito à dignidade humana. In: SILVA, Luciana Aboim Machado Gonçalves da (org.). Mediação de conflitos. São Paulo: Atlas, 2013. p. 63-93.

WARAT, Luis Alberto. Territórios desconhecidos: a procura surrealista pelos lugares do abandono do sentido e da reconstrução da subjetividade. Florianópolis: Fundação Boiteux, 2004a.

WARAT, Luis Alberto. Prefácio. In: MEZZAROBA, Orides et al. Surfando na Pororoca: ofício do mediador. Florianópolis: Fundação Boiteux, 2004b. V. III.

WARAT, Luis Alberto. O ofício do mediador. Florianópolis: Habitus, 2001. V. 1.

WARAT, Luis Alberto. Pensemos algo diferente em matéria de mediação. In: SPENGLER, Fabiana Marion; LUCAS, Douglas Cesar (org.). Justiça restaurativa e mediação - políticas públicas no tratamento dos conflitos sociais. Ijuí: Editora Unijuí, 2011.

WARAT, Luis Alberto. A rua grita Dionísio. Direitos humanos da alteridade: surrealismo e cartografia. Rio de Janeiro: Lumen Juris, 2010.

WATANABE, Kazuo. Acesso à justiça e sociedade moderna. In: Participação e processo. São Paulo: Ed. Revista dos Tribunais, 1988. 